\title{
From Semantics to Semiotics: Demystifying Intricacies on Translation Theory
}

\author{
Baseel A. AlBzour (Corresponding author) \\ Department of English Language and Literature, Al AlBayt University (AABU), Mafraq, Jordan \\ E-mail: bbbzoor@yahoo.com \\ Naser N. AlBzour \\ Department of English Language and Literature, Al AlBayt University (AABU), Mafraq, Jordan \\ E-mail: nnnbzour@gmail.com
}

Doi:10.7575/aiac.alls.v.6n.5p.121

Received: 20/05/2015

URL: http://dx.doi.org/10.7575/aiac.alls.v.6n.5p.121

Accepted: 25/07/2015

\begin{abstract}
The implications of any linguistic and non-linguistic research can be always of paramount importance when carefully and cleverly integrated within the scope of any interdisciplinary field of translation study. The major goal of this paper, therefore, is to highlight and stress how a semiotic approach to the theory of meaning, in general, and to translation theory, in particular, can critically subsume the mere linguistic concerns of any prevalent semantic approach to translation. On the one hand, the former sets justifiable priorities that can more thoroughly cater for the dynamism of all textual, co-textual, extratextual, contextual and paratextual layers of the text as a fully-fledged sign within an overall sophisticated yet systematic macro order of signification; on the other hand, the latter usually may fumble and stumble whenever a text bears over-laden content of basic signifying elements that soar beyond the narrow limitations of lexical and sentential compositional structure. Thus, this paper advocates a strict semiotic approach to translation theory through which an array of semiotic annotations of the SLT must be aligned with and incorporated into basic morphosyntactic notations, semantic denotations and sociocultural connotations.
\end{abstract}

Keyword: Semiotics, semantics, translation studies, translation methods, compositionality, sign, sign-shift, text, context

\section{Introduction}

Translation theory and translation studies have been under overt hegemony of extraneous fields of humanities for ages. Linguistics in general and semantics in particular can be one of these dominantly motivating factors that translation theoreticians have invariably relied upon in their analyses since the onset of the twentieth century. This terse research is dedicated to presenting and analyzing basic semiotic factors that critically affect translation theory that has been under the spill of semantic approaches for ages. It thus draws upon major sociocultural and historical background of Arabic and English to help researchers better understand the significance of highlighting the impact of semiological interaction of the signifying order beyond the mere limitations of lexical and sentential semantics; and thus it constitutes a threshold of an approach to establishing a logical point of departure for many forthcoming works to explore many other relevant issues from such a comprehensive perspective by eliciting and shedding light on some indispensible cultural and linguistic variables of both source and target languages; these variables, of course, should include differences as well as similarities (cf. Hawkes 2003).

Arabic and English can be mainly referred to as far as the scope of this paper is concerned. Historically speaking, Arabic language has been the frame within which Arabic culture has been encapsulated all through long ages. Classical Arabic was intuitively and orally learned from ancient times till the golden ages of the Islamic era when battalions of different peoples of non-Arabic tongues embraced Islam. Hence, the need emerged to teach Arabic in written forms in order to absorb those newcomers as well as preserving the correct nature of Arabic language (see Brockelmann 1960, Gibb 1962, et al). Apparently, the pre-Islamic era, which was mainly characterized by idolatry and paganism, paid a great deal of significance to Arabic language because the rhetorical impact and eloquent traits of this language were used as a shield and a weapon by those clashing tribes. The major concern of those people was to manifest self-dignity and pride as opposed to other tribes or clans within the same tribe. Heroism and chivalric ideals were the most appreciated traits commemorated by these tribes. The same would be true to some extent in the case of English for ages.

It goes without saying that translation is a written mode of both interlingual and intercultural communication that has been indispensably exploited since the dawn of primitive cultures. Both linguistically and culturally, language manifests uniquely interacting features that may constitute a real challenge to translation theory and to those who are active in the field whether practitioners or theoreticians. Its crucial role has been of undeniable significance at various economic, cultural, scientific and political levels to the extent that the twentieth century was described by Jumpelt (1961) as the 'age of translation'. Ancient as the vast empires of ancient Rome, Persia and Greece, translation studies have never 
engendered a unified theory that enables translators to outright follow straightforward and systematic principles that may lead to optimal translation as such as it can be understood when Newmark (1981) critically summarizes this controversial state of affairs in the following lines as he ponders:

Translation theory is a misnomer, a blanket term, a possible translation, therefore a translation label, for Ubersetzungwissenschalft. In fact translation theory is neither a theory nor a science, but the body of knowledge that we have and have still to have about the process of translating.

\section{Theoretical Constructs}

Translation theory in essence resembles to a great extent the dilemma of the Procrustean bed because any translated work is oftentimes assessed within a strict dichotomy that stretches the text on the two edges between undertranslation, on the one hand, and overtranslation, on the other hand (AlBzour 2011). Therefore, the translator has always to be either racked or amputated, and this is the fatal motif that always results in the perplexity of losses vs. gains in translation (Nida:1965, Catford: 1964, Nida:1989, et al). The prime concern of many linguists and philosophers for centuries has been to set a proper equation that can best handle the entanglement between linguistic components and cultural ones where translation operates and feed somewhere on both. Pertinently hovering around the polemical linguistic theories, this controversial argument can be ascribed in the first place to the obviously fuzzy nature of the word 'culture'. This can be easily captured if one closely examines the following classic definition proposed by Edward Taylor $(1871,1)$ : "Culture or Civilization, taken in its wide ethnographic sense, is that complex whole which includes knowledge, belief, art, morals, law, custom, and any other capabilities and habits acquired by man as a member of society".

In light of such anthropological constructs, many assumptions and hypotheses have been debated in an attempt to fathom the enigmatic relation between language and culture. One of these was strongly proposed by Sapir-Whorf, who simply claim that language predetermines what and how we perceive our surroundings. Therefore and in relation to thought and reality, language is our own filtering device, "We see and hear and otherwise experience very largely as we do because the language habits of our community predispose certain choices of interpretation." Sapir (1958: 69).

The impacts of such an assumption has resonated to thousands of ethnographers, linguists and translators as well; and thus this triggers many claims of 'impossibility' of communication and thereby translation o cross-culturally and cross. Nonetheless, it is evident that many linguistic and cultural gaps can be systematically bridged due to the dynamic nature of translation as a process as well as the dynamism of the semiotic behavior of all languages and all cultures. This can explain what Beaugrande $(1980,1991)$ proposes as he maintains that translation studies should shift to dealing with more systematic fields of text linguistics instead of focusing on 'incidental incompatibilities' and this can guarantee more communicative effects because languages share lots of similarities. This dynamic approach lends itself flexibly to consider all pertinent disciplines such as semantics, pragmatics, sociolinguistics, stylistics and thus semiotics in an attempt to work within an interdisciplinary paradigm that prioritizes the essential needs through which communicative functions can be best attained prior to mere linguistic forms. Therefore, one can clearly probe the urge for cultural semiotics as restated by Danesi and Perron $(1999,55)$ :

the semiotic agenda is shaped, by and large, by a search for the biological, psychic and social roots of the human need of meaning... As an applied interdisciplinary science, cultural semiotics enlists not only the notions of theoretical semiotics in its investigation of cultural forms of expression, but also the insights coming out of the cognate fields of psycoloanalysis.

In his acknowledged Approaches to Translation, Newmark (1981) elaborates on two main parts of this moot issue. The first part deals with: Aspects of Translation Theory, and the second deals with 'Some Proposition on Translation'. The main reason for formulating a translation theory, for proposing methods of translation related to and derived from it, for teaching translation, for translation courses is the 'appalling badness of so many published translation' (Widemer 1959). In addition, Newmark $(1981,1988)$ argues that translation theory derives from comparative linguistics; and within linguistics, translation is mainly an aspect of semantics, so all questions of semantics can be closely related to translation theory. Since semantics is often presented as a cognitive subject without connotations, rather an exercise in communication, semiotics can be an essential factor in translation theory, so this explains why Peirce (1934) stresses the communicative factor of any sign.

A translator essentially needs knowledge of literary and non-literary textual criticism. Both Savory (1957) and Reiss (2000) confirm that the technical translator is concerned with content while the literary translator should be keen on form, on the contrary, it has been sometimes stated that a technical translation must be literal; a literary translation must be free; a translator must respect good writing scrupulously by accounting for it's language, structure and content (see Nida and Taber 1969). On the other hand, the study of logic will assist the translator to assess the truth values underlying the passage he is translating. Philosophy, therefore, is a fundamental issue in translation theory. Grice's 'meaning means intention' helps the translator to detect the appropriate and intended meaning. Usually, a text's or a proposition's intention can be ascertained only outside the utterance. Newmark (ibid). 
Newmark always presents and tends to evaluate some theoretical literature. Nida (1964), on the other hand, adopts the mainstream of transformational grammar by proposing eight model kernel sentences as traditional stages between source and target language structures. He applies componential analysis, and discusses the logical relations of words with each other, the differences between cultural and linguistic translation, and the difficulties of translating between remote cultures. Furthermore, Fedorov $(1958,1968)$ stresses that translation theory is an independent linguistic discipline, so he strongly believes that all experience is translatable. Equivalence issues have been shed light on a plethora of heated discussions because of the complexity of the scope of equivalence as it can be perused through Komissarov's theory of equivalence since it distinguishes five major levels in this regard: lexical units, collocation, information, situation, and communication aim.

Firth (1968) subtly points to contextual meaning as the basis of translation theory and perceives translation theory as the basis of a new theory of language and firmer foundations in philosophy. Vinay and Darbelnet (1976) enumerate seven procedures that can be in process while translating: transliteration, loan translation, literal translation, transposition, modulation, equivalence and adaptation. Thus one can conclude at this stage that there is a wide but not universal agreement that the main aim of the translator is to produce as nearly as possible the same effect on his readers of the original (Nida 2002). All texts may be regarded by the translator as an amalgam of standardized and non-standardized language. The distinction between them is that for standardized language, when it is used as such, there should be only one correct equivalent, provided one exists, provided it is used in the same situations by the same kind of person, and that is the 'science of translation'. While for non-standardized language there is rarely only one correct equivalent, and that is the art or craft of translation (Newmark1991).

\section{Semiotic Ends vs. Semantic Methods}

The prime goal of this paper is to defend how semiotics can successfully provide a solid ground for translation theory as it concentrates on the actual ends of the mechanism of meaning. Both semantics and semiotics do approach the issue of meaning and its pertinent realizations at various levels. However, the scope of each is different; the tools are different and thus the results must be different too. Semantics prioritizes lexical and sentential content while semiotics does look for a systematic description not only of sign structure but also and ultimately sign interaction. Consequently, the way each discipline handles and perceives translation must be disparate in means and ends. According to many theoreticians, the main concern of translation theory is to determine appropriate translation methods for different text categories. Translation theory should provide a framework of principles, restricted rules and hints for translating texts and criticizing translations. It is an attempt to give some insight into the relation thought, meaning and language; cultural and individual aspects of language and behavior as well as the understanding of cultures (Newmark 1981, Nida 1994, Nida 2000, et al). To understand and analyze the text first and thus to make some generalizations about it characterize the task of any theoretician. Therefore, there are certain priorities that a professional translator should bear in mind before commencing on translating the text itself ; mainly, the intention of the text, the intention of the translator, the reader, the setting of the text, the quality of writing and the authority of the text as Newmark $(1981,1993)$.

One the other hand, the translator should be quite familiar with the semantic, syntactic and stylistic aspects of the text, which in turn can engender different types of texts as it can be explicitly represented in various kinds of authoritative texts, personal notes and diaries, academic textbooks, academic papers, magazines, newspapers, etc. All these aspects of sophisticated considerations beg the need for a semiotic paradigm in translation where the unity of the text is in tandem with the unity of the sign dynamism as a whole. The simplistic distinction made by Newmark $(1981,1993)$ hinges upon a neat dichotomy of method implementation: (a) communicative translation, where the translator attempts to produce the same effect on the TL reader as was produced by the original on SL reader. (b) Semantic translation, where the translator attempts to reproduce the precise contextual meaning, so this envisages lexical items in three different ways:

a) having four types of senses: concrete, figurative, technical, and colloquial sense.

b) having four degrees of frequency; primary, secondary, collocational, nonce.

c) core and peripheral: the core meaning includes all the essential senses.

Accordingly, it can be argued that translation theorists are primarily concerned with translation procedures. These translation procedures vary between mandatory constants and optional variables. Hence Newmark (1981) cites almost a dozen of such conducive procedures such as Transcription, Through translation, Lexical synonymy, TL equivalent, Componential Analysis, Transposition, Grammatical Replacement, Modulation, Compensation, Cultural Equivalence, Translation Label, Definition, Paraphrase, Expansion and Notes. Such views channel the argument towards what translation theory can and cannot do. In a nutshell, translation theory cannot and should not aim at giving birth to good translators as such; rather it provides a framework for translators to consider but not to follow while reading, analyzing and translating a text.

However, one might argue about the significance of the text itself that translators handle while undertaking their daily tasks. There is no doubt that authoritative literary texts are the most challenging among all. Different views of translating literature can be considered in this regard. Jacobson (1967) argues about the intranslatability of poetry; thus, he argues, "poetry by definition is untranslatable. Only creative transposition is possible." So he denies the possibility of translating poetry even into poetry, unlike few theoreticians who believe that any kind of literary genres can be even translated into prose. Tytler $(1791,111)$, on the other hand, believes that some poetic texts can be acceptably translated into prose while it is impossible to do so in many other cases; therefore, he maintains, "it is impossible to do complete 
justice to any species of poetical composition in a prose translation; in other words, that none but a poet can translate a poet". Of course this claim resonates to some scholars, yet lacks strong validity because many successful translators are neither poets nor playwrights; however, if a translator enjoys the skill of such poetic writing, it can be of some advantage that marks his/her outstanding performance.

Accordingly, the prime concern of the translator may diverge to cover and take care of many priorities while handling any creative text: its meaning, its beauty and its author's unique touches.

In other words, he/she should always bear this very question in mind: is his translation going to be audience-oriented, text-oriented, author-oriented, or all of these things together?! "Next in importance to a faithful transfusion of the sense and meaning of an author is an assimilation of the style and manner of writing in the translation to that of the original" Tytler (ibid, 63). On the other hand, Gorjan $(1970,201)$ rejects the idea of having any perfect faithful translation especially in such authentic literary texts. Thus, he eloquently maintains that translation only mirrors the SLT, and "sometimes the image is clear, sometimes it is vague and ill-defined, and this depends largely on the various qualities specific to the language from which and into which it is translated ."

A perusal of major translation theories would reveal the fact that most these theories operate within a scale of polarity that ranges between 'communicative' vs. 'semantic' translation. To one of these extreme edges stands Catford (1965) representing the formalist school of translation, thus perceiving translation as a formal process of replacing a certain text in the SL with its equivalent counterpart in the TL. To the other extreme appears Nida (1964) who conspicuously depicts translation as a process of searching for functions between the SL and the TL, thus giving slight attention to rigid forms. He, therefore, proposes a dynamic equivalence with great emphasis on the 'closest natural effect' that maintains the force of the SL rather than the form (See AlBzour 1997).

Banking on these two kinds of antithetical views, various methods, strategies and techniques have been proposed and counterargued under different terminological clichés and headings such as formal equivalence, functional equivalence, dynamic equivalence and ideational equivalence (see Fargahl 1994). Consciously or unconsciously, translators usually opt for various strategies and techniques of translation. Newmark (1988) pinpoints a number of these strategies that can describe what translators may do in various circumstances. Technically, such strategies mainly consider semanticallyoriented aspects of translation and thus they narrow down translation theory to a mere lexical quest. Therefore, when certain lexical or referential gaps textually permeate, transference or loan words is commonly resorted to, i.e. the translator has to preserve the original source language words (SLW) and render them into target language words (TLW).

However, naturalization is a concomitant strategy that usually accompanies any process of transference and borrowing as an inevitable result of phonological or morphological lack of correspondence between the SL and the TL (Nida 2003).

Newmark (1988) argues that the whole translation process can be deemed as an issue of matching synonymy between languages. Nonetheless, this rosy vision can be very optimistic as far as translation is concerned because total or absolute synonymy can never exist within the same language (Lyons 1977). However, other degrees of synonymity such as cognitive and near synonyms do exist; therefore, it would be more feasible for translators to lead their quest within approximation limitations instead of synonymous cognates and counterparts. Such a noble enterprise can be enhanced when componential analysis is in effect, yet such factorial analysis is very limited when closed approached and deeply examined since many basic features can be debated in principle when a huge number of lexemes are set under semantic scrutiny within the same SL, let alone the dilemma of so doing when the impact is intended to cater for similar lexemes in the TL (see Petrilli 2003).

At the structural level where morphological and syntactic features are in operation, transposition is usually prescribed because the syntactic and grammatical incongruity between the SL and the TL is always evident. This gives translators a scope of relative flexibility and freedom to make some alternations in terms of word order, agreement, gender, number and so on and so forth, yet the scope of such maneuvers would never exceed the sentential boundaries. In the same vein, modulation can be somehow helpful within the sentential domain with some communicative orientation as it tends to guarantee a degree of natural flow in the TLT, so it sets the initial foundations for discoursally-sought renditions with restricted flexibility that would not exceed some syntactic aspects as well; this may cover basic contrastive issues such as passive and active voice, distribution of cause and effect as well as some aspects of modality and totality.

Functionally, some other strategies can be exploited such as Functional equivalence through which translators aim at reproduce similar effects at a larger textual level, i.e. transferring a SLT in the TLT. However, specific cultural and linguistic features usually vanish for some considerations appertaining to presumably attained naturalness and idiomaticity. For some structural and functional motivations, compensation strategies can be implemented to guarantee the least degree of the so-called 'loss of meaning'. However, any kind of compensation would never make up for any loss as such; rather it would result in some 'gain' because the sign system does not allow any sign modification without consequent sign interaction beyond the level of mere shades of meaning (cf. Robin 1996).

Worse than that is the trend that advocates reduction and expansion as a core strategy that may help translators avoid unnatural and undesirable impacts in their renditions at the very expense of the fundamental principle of faithfulness to the SLT. Therefore, translators are given a considerable amount of freedom to add, to drop and to modify certain structural and lexical segments that may spoil the delivery of the intended meaning and the probabilities of relevant 
communicative effects. All in all, such endeavors are neat in theory but usually very subjective and may result in severe distortion and jeopardy in practice. To add insult to injury, paraphrase is often prescribed for semantic purposes to handle any potentially undesired components and lexical incongruities or even sentential oddities. The whole process is based on recreating a replica of the propositional content of a number of sentences (see Lyons 1977).

Semantically, this can easily work; however, the risks can be more decisive at the pragmatic level, the discoursal level and the cultural level because the signifying order follows a strict mechanism where each sign affects and gets affected by its companions since translation is not a mere process of rewriting (cf. Anderson 2003). Therefore, the last haven that translators usually resort to when stuck is to provide footnotes and endnotes in order to achieve a couple of goals. First, translators try to avoid any sort of misunderstanding that may result due to lexical gaps, lexical incongruities or cultural mismatches and subsequent vagueness or ambiguity. Second, translators venture to strike ambitious balance between extremes of loyalties, i.e. being faithful to the SLT and being faithful to the TL audience. Semiotically, the results in such cases are disastrous because the process of translation undergoes various stages of continuous interruption as well as a margin of inaccurate and erroneous effects that the text can create as unified and uninterrupted sign that resists intruding signs and that rejects dispersion (see Halliday 1978). The claim that maintains the existence of 'ideational equivalence' is absurd and useless (cf. Farghal 1994) because this sort of unrealistic equivalence is erroneous based on Jackbsonian and Hallidayan paradigms of ideational meaning where meaning is classified not only according to its syntactic and semantic structure; rather, it essential hinges upon sociocultural factors and implications.

To present a neat and comprehensive semantic approach to translation, Newmark (1988) makes distinctions between translation as an art, translation as a skill and translation as science. He, therefore, stresses that Translation is an art when poetic texts are involved; this entails that translating other texts would be less artistic and thus more scientific. Such categorizations and taxonomies are buyable only when one is looking for an ease of description, but it ignores the very essence of translation as a complicated process that requires a professional expertise that incorporates the skill of interpreting and using the signs, the art of portraying all signs within a picture and the skill of running the system that operates these signs. This entails that drawing borderlines between these components can be superficially elegant from a semantic perspective but luxuriously inefficient Semiotically (AlBzour 2011).

One of the best examples that can highlight the serious problem of semantically oriented solutions and propositions can be seen in Abu-Ghazaleh (2003). He is a professor of translation who tends to follow and copy Newmark's theoretical approach in every single field of his argument, so he presents most aspects of the theoretical framework that has been reviewed so far. Then he tries to demonstrate some features of the problem by pointing to some implementations of such theories and procedures of English-Arabic translation. Therefore, he goes over many classified topics pertaining to problems that face translators from Arabic into English and vice versa; he explicitly proposes his own presumed solutions based on his diagnosis of each problem as such. In his opinion, translation is always possible, yet problems are inevitable. However, translators can overcome these problems because equivalents do exist more often than not. The approach he is advocating seems too simple and it may mainly help beginners in translation, but it can be useless for professionals and practitioners.

In his analysis for instance, translators need first to examine the real nature of the linguistic barriers. For example, he refers to doubleness or even sometimes multifoldedness of meaning and its relevant aspects or causes especially ambiguity, which is commonly used by punsters to produce punning effect. Ambiguity, of course, is a case where a word, phrase, or sentence which has more than one meaning, and this ambiguity can be grammatical e.g. 'The lamb is too hot to eat'; lexical polysemous ambiguity e.g. 'face' of a human or a building ; or homonymous ambiguity e.g. ' bank ' of a river or of money. Homonymy vs. Polysemy. Such an argument can trivialize what translation theory is all about. The focal point of argument here, therefore, does not stem from the manipulation of polysemy, homonomy and homophony; nor how to differentiate between homonymy and polysemy; rather, it is the dilemma of how such words are set within the sign system and how their cognitive behavior contribute to our schematic world knowledge, and how they sequentially lend themselves easily or not to a systematic process of translation (see Palmer 1981).

A great classic domain of sign relations that may reveal how such universal schemata can be approached is the metaphorical behavior of lexical extension that triggers systematic semantic changes cross-linguistically. Such symmetrical cognitive dimensions assure how we unconsciously set our verbal and nonverbal interaction oftentimes metaphorically without paying heed to such sophisticated processes (see Lakeoff 1980). No doubt then that such a realistic approach must benefit from the dynamism of our signifying order as a linguistically-privileged organism. Because 'a word would suffice the wise', the totality of the signs and their semiotic analysis can overshadow the mere semantic interest as it is evident in the intralingual interpretation of the English proverb 'a rolling stone gathers no moss'. The semiotic dimension that may explain the opposite directionality of the total sign embodied in this proverb is well-established in the way such a phrase is decoded in Britain in a specific way contrary to the one decoded by the other users behind the Atlantic in the United States. Britons admire immobility while Americans commend mobility, so it is commendable to remain stable in the former case while it is condemnable in the latter. Such paradoxical understanding can show how compositionality at the lexical and the sentential level can yield an inappropriate message while the entirety of the proverb can be only decoded as long as it is approached as one sign as such. The implications of this approach may substantially affect the need to redirect the compass of future translation studies towards sign shifts instead of morphological, syntactic and semantic shifts. 


\section{Conclusion}

To conclude, it may sound over-simplistic to narrow down the scope of translation theory to semantics or any linguistic discipline proper because semantics only touches upon a fixed number of lexical and sentential issues that concern some prospects of meaning and meaning theory. This can by no means be intended to underestimate the role of semantics; rather, it specifically aims at providing a feasible approach that can more comprehensively and more adequately describe, diagnose and give insight into what translation theory is all about; what integral components can be involved and incorporated; how such components operate at various linguistic and non-linguistic levels and how they do systematically interact in the final analysis. The researchers claim that the most appropriate and maybe most flexible and dynamic approach to achieve such vital goals can be a sign-triggered perspective that cogently elicits how semiotics is always in effect as long as meaning is concerned and as far as this meaning is species-specific. Therefore, the rudimentary pursuits for fabricated sorts of perfect equivalents or semi-equivalents are doomed to utter failure unless the whole text is communicatively taken as a single micro-sign that operates within a wider macro-sign and sign system in totality.

\section{References}

Abu-Ghazala, H. (2003). Translation as Problems \& Solutions. Dar wa Maktabat Al-Hilal.

AlBzour, N. (1997). Context Paramouncy in Translating Formulaic Expressions with a Theistic Reference: Sociopragmatic Perspective. Unpublished MA Thesis. Yarmouk University.

AlBzour, N. (2011). Semio-Pragmatic Analysis of Cartoons Discourse: a Step towards Semio-Translation. Unpublished Ph.D. dissertation. Purdue University.

Anderson, M. (2003). Ethnography as translation. In Susan Petrilli (Ed.), Translation Translation. New York: Rodopi, 389-97.

Beaugrande, R. de. (1991). Semiotics and control systems. In Myrdene Anderson and Floyd Merrill (Eds.) On Semiotic Modelling. Berlin: Mouton de Gruyter. 285-323.

Beugrande, R. de. (1980). Text, Discourse, and Process: Toward a Multidisciplinary Science of Texts. Norwood, N.J: Ablex.

Beaugrande, R. de., and Dressler, W. (1980). Introduction to text linguistics. London: Longman.

Bennett, J. M. (1977). Transition shock: Putting Culture Shock in Perspective. International and Intercultural Communication Annual, 4, 45-52.

Berry, J.W. (1966). Temne and Eskimo perceptual skills. International Journal of Psychology, 1, 207-229.

Bock, P.K. (1988). Rethinking Psychological Anthropology: Continuity and Change in the Study of Human Action. San Francisco: Freeman.

Bond, M. H., \& Cheung, M.K. (1984). Experimenter language choice and ethnic affirmation by Chinese trilinguals in Hong Kong. International Journal of Intercultural Relations, 8, 347-356.

Brewer, M. B., \& Gardner, W. (1996). Who is this "we"? Levels of collective identity and self representations. Journal of Personality and Social Psychology, 71, 83-93.

Brockelmann, C. (1960). History of the Islamic Peoples. New York: Capricorn Books.

Catford, J.C. (1965). A Linguistic Theory of Translation: An Essay in Applied Linguistics. London: Oxford University Press.

Danesi, M., and Perron, P. (1999). Analyzing Cultures: an Introduction and Handbook. Indiana: Indiana University Press.

Farghal, M. (1994). Ideational equivalence in translation. in R. de Beaugrande, A. Shunnaq and M. Heleil (Eds.), Language, Discourse and Translation in the West and Middle East. Amsterdam: John Benjamins Publishing Company.55-63.

Firth, J. R. (1968). Linguistic analysis as a study of meaning. in F. R. Palmer (Ed.). Selected Papers of J. R. Firth 19521959. London: Longmans.

Geertz, C. (2000). Interpretation of Cultures. New York: Basic Books.

Gibb, H.A. R. (1962). Studies on the Civilization of Islam. Beacon Press, Boston.

Halliday, M.A.K. (1978). Language as Social Semiotics: the Social Interpretation of Language and Meaning. London: Edward Arnold.

Hawkes, T. (2003). Structuralism and Semiotics. London and New York: Routledge.

Herskovits, M. J. (1955). Cultural Anthropology. New York: Knopf.

Huntington, S.P. (1996). The Clash of Civilizations: Remaking of World Order. New York: New York Press.

Jakobson, R. (2000). On linguistic aspects of translation. In L. Venuti (Ed.) Translation Studies Reader. London: Routledge. 113-19. 
Jumpelt, R.W. (1963). Methodological approaches to science translation. In Cary, Edmond \& Rudolf W. Jumpelt (Eds.). Quality in Translation. La qualité en matière de traduction. New York: Macmillan, 267-81.

Lakoff, G., and Johnson, M. (1980). Metaphors We Live By. Chicago: Chicago University Press.

Lyons, J. (1977). Semantics. Cambridge: Cambridge University Press.

Melrose, R. (1996). The Margins of Meaning: Arguments for a Postmodern Approach to language and Text. Amsterdam: Rodopi.

Munday, J. (2001). Introducing Translation Studies. Theories and Applications. London: Routledge.

Newmark, P. (1993). Paragraphs On Translation. Clevedon: Multilingual Matteres.

Newmark, P. (1991). About Translation. Clevedon: Multilingual Matters.

Newmark, P. (1988). A Textbook of Translation. New York: Prentice Hall.

Newmark, P. (1981). Approaches to Translation. Oxford: Pergamon Press.

Nida, E. (2003). Language and culture. In Petrilli, (Ed.). Translation. New York: Rodopi, 413-24.

Nida, E. (1992). Translation: Possible and Impossible. Turjuman 3 (2): 147-63.

Nida, E. (1964). Toward a Science of Translating: With Special Reference to Principles and Procedures Involved in Bible Translating. Leiden, E.J. Brill.

Nida, E. A., and Taber, C. (1969). The Theory and Practice of Translation. Leiden: Brill.

Palmer, F.R. (1981). Semantics. Cambridge: Cambridge University Press.

Peirce, Ch. S. (1931-1958). Collected Papers of Charles Sanders Peirce. Vols. 1-6, C. Hartshorne and P. Weiss, (Ed.) vols. 7 \& 8. A. W. Burks, Ed. Belknap Press, Harvard University Press.

Petrilli, S. (2003). The Intersemiotic character of translation. In Susan Petrilli, (Ed.), Translation Translation. New York: Rodopi, 41-53.

Reiss, K.(2000). Type kind and individuality of text: Decision making in translation. K. Kitron (Trans.) In Venuti, L. (Ed.). The Translation Studies Reader. London: Routledge, 160-71.

Sapir, E. (1958). Culture, Language and Personality. Berkeley, CA: University of California Press

Savory, T. H. (1957). The Art of Translation. Jonathan Cape: University of Michigan.

Tytler, A. F. (1791). Essays on the Principles of Translation. London: Everyman's Library.

Vygotsky, L. S. (1978). Mind in Society. Cambridge, MA: Harvard University Press. 